\title{
Research continues to identify risks marijuana poses to adolescents, including the path to heroin
}

\author{
Volume 6 Issue 4 - 2017
}

\section{Opinion}

The human brain, especially the prefrontal cortex (PFC), is slow to develop, not completing well into our twenties. This slow development may explain some adolescent and teen behavior. Kids sometimes fail to see the consequences of their actions. When it comes to drugs, kids are often tempted to explore. The consequences of exploration may be severe. The combination of today's potent cannabis, which may contain as much as $30 \% \mathrm{THC}$, and the fact that kids receive mixed messages and false information regarding cannabis safety, has complicated the overall discussion about marijuana safety. Many consider marijuana a safe drug with no negative health effects. However, almost any adult and most adolescents would agree that heroin use is a serious problem, presenting many health concerns. Recent research suggests the link between marijuana use and opiates such as oxycontin and heroin may be stronger than previously suspected. Studies by Yale University indicate marijuana use leads to prescription drug abuse, such as with oxycontin. ${ }^{1}$ Very recent research indicates non-medical use of prescription opiates predicts transition to heroin later in life. ${ }^{2}$ For several years, NIDA research has been focusing on how marijuana addiction mechanisms work. ${ }^{3}$ When a serious cannabis habit leads to curiosity about prescription opiates like oxycontin, heroin use and addiction may become difficult to prevent. Kids can become addicted to drugs like oxycontin very fast. Often this habit becomes too expensive to maintain and hooked teens will substitute oxycontin with less expensive, but highly available opiate drugs like heroin.

Recent experiments from Mount Sinai, $\mathrm{NY}^{4}$ indicate young rats dosed with THC produce offspring with modified reward systems. Genetic changes cause the animals to increase operant effort for heroin. To extrapolate to humans, this means kids who have never taken drugs, could be at greater risk for heroin addiction, because of their parent's marijuana habit.

Now we are seeing evidence of high potency marijuana associated to stroke in healthy young people. Marijuana can alter blood pressure, constrict systemic and brain blood vessels, reduce or block blood flow, thus potentially inducing stroke. ${ }^{5,6}$

It's critical to appreciate marijuana naïve kids are unlikely to wake up one day and say: "today I think I will try heroin." Marijuana is often used in social groups that foster curiosity, exploration and some rebellion. In short, getting high on pot with friends creates a drug friendly environment. This has always been a concern regarding the gateway effect. Legalizing medical marijuana may reduce kid's safety concerns. Some studies show kids use marijuana at an increased rate when medical marijuana was recently legalized in their community. ${ }^{7}$

Marijuana impairs many different cognitive domains. It is well known that marijuana impairs memory and attention in adolescents and adults. ${ }^{8,9}$ Chronic pot smoking can even lead to reduced IQ scores. ${ }^{10}$ For the first time, changes in brain architecture, including reductions (damage) to critical white matter, are associated with heavy smoking, specifically high potency marijuana. ${ }^{11,12}$ All of these marijuana induced cognitive impairments could lead to poor decision making on the path to heroin.

\author{
Rick Brucato \\ Cascade Chemical Biology, USA \\ Correspondence: Rick Brucato, Cascade Chemical Biology, \\ Princeton Corporate Plaza 9 Deer Park Dr., Suite K8 \\ Monmouth Junction, NJ 8852, USA, \\ Email rickbrucato@rocketmail.com
}

Received: March 16,2017 | Published: April 10, 2017

It is critical parents and kids have accurate information to help make decisions about risk and their health. One constantly updated source is "NIDA for teens," https://teens.drugabuse.gov/. The promarijuana industry is growing stronger every day. The incredible profit margins drive a natural enthusiasm that is supporting this industry and cannabidiol or CBD, associated with some potential medical benefits may prove to be medically beneficial, although the DEA has yet to recognize any bona fide medical benefit from marijuana use. The marijuana industry's enthusiasm must be balanced with good judgment. We must remind ourselves the early tobacco industry went through very similar growing pains, except there was a clear problem when it came to transparency and data the public should have known about. Because of kid's unique brain physiology and development profile, adolescents remain in the crosshairs of many of marijuana's most dangers characteristics. While the medical and scientific community is quite concerned about marijuana's effect on kids, especially the new high potent strains, concerned individuals and communities are overwhelmed by our new pro-marijuana culture. It is up to the scientific and medical community to be open minded about any benefits that marijuana may confer, yet protect and educate our most vulnerable population-kids. We must be willing to share the truth about marijuana's position in the path to heroin addiction, the dangers it poses to those at risk for serious mental illness and the real data showing marijuana harms cognition in kids.

\section{Acknowledgments}

None.

\section{Conflicts of interest}

None.

\section{Funding}

None.

\section{References}

1. Fiellin LE, Tetrault JM, Becker WC, et al. Prior use of alcohol, cigarettes, and marijuana and subsequent abuse of prescription opioids in young adults. J Adolesc Health. 2013;52(2):158-163. 
2. Cerdá M, Santaella J, Marshall BD, et al.Jun 6. Nonmedical Prescription Opioid Use in Childhood and Early Adolescence Predicts Transitions to Heroin Use in Young Adulthood: A National Study. J Pediatr. 2015;167(3):605612.

3. Hirvonen J, Goodwin RS, Li CT, et al. Reversible and regionally selective downregulation of brain cannabinoid CB1 receptors in chronic daily cannabis smokers. Mol Psychiatry.2012;17(6):642-649.

4. Szutorisz H, DiNieri JA, Sweet E, et al. Parental THC Exposure Leads to Compulsive Heroin-Seeking and Altered Striatal Synaptic Plasticity in the Subsequent Generation. Neuropsychopharmacology. 2014;39(6):1315-1323.

5. Rumalla K, Reddy AY, Mittal MK. Association of Recreational Marijuana Use with Aneurysmal Subarachnoid Hemorrhage. J Stroke Cerebrovasc Dis. 2016;25(2):452-460.

6. Hemachandra D, McKetin R, Cherbuin N, et al. Heavy cannabis users at elevated risk of stroke: evidence from a general population survey. Aust N Z J Public Health. 2015;40(3):226-230.
7. Stolzenberg L, D'Alessio SJ, Dariano D. The effect of medical cannabis laws on juvenile cannabis use. Int J Drug Policy. 2016;27:82-88.

8. Chen R, Zhang J, Fan N, et al. Delta 9-THC-caused synaptic and memory impairments are mediated through COX-2 signaling. Cell. 2013;155(5):1154-1165.

9. Fontes MA, Bolla KI, Cunha PJ, et al. Cannabis use before age 15 and subsequent executive functioning. Br JPsychiatry. 2011;198(6):442-447.

10. Meier MH, Caspi A, Ambler A, et al. Persistent cannabis users show neuropsychological decline fromchildhood to midlife. Proc Natl Acad Sci U S A. 2012;109(40):E2657-E2664.

11. Shollenbarger SG, Price J, Wieser J, et al. Impact of cannabis use on prefrontal and parietal cortex gyrification and surface area in adolescents and emerging adults. Dev Cogn Neurosci. 2015;16:46-53.

12. Wise J. Skunk-like cannabis may damage white matter in the brain, study shows. BMJ. 2015;351:h6417. 